\title{
Could pollen extract in association with vitamins be favorable in the reduction of chronic prostatic inflammation? A case-series analysis
}

\author{
Michele Zazzara ${ }^{1}$, Arjan Nazaraj ${ }^{1}$, Ottavio Colamonico ${ }^{1}$, Marcella Mastromauro ${ }^{2}$, Giuseppe Cardo ${ }^{1}$, \\ Giuseppe Mario Ludovico ${ }^{1}$ \\ ${ }^{1}$ Urology Department, Ospedale Generale Regionale "F. Miulli", Acquaviva delle Fonti (BA), Italy; \\ 2 Pathological Anatomy Department, Ospedale Generale Regionale "F. Miulli", Acquaviva delle Fonti (BA), Italy.
}

\begin{abstract}
Summary The aim of the present case-series analysis was to assess the safety and efficacy of pollen extract in association with vitamins in order to reduce the chronic prostatic inflammation in patients with class IV chronic prostatitis (CP). Nineteen non-consecutive patients performed a prostate biopsy for a suspect of prostate cancer. The biopsy histopathological examination showed a class IV $C P$, in presence of mild/moderate/high degree of inflammation, in association with an extensive (multiple biopsy sites, i.e., $\geq 3$ ) high-grade prostatic intraepithelial neoplasia PIN (HGPIN) and/or atypical small acinar proliferation (ASAP). According to EAU Prostate Cancer Guidelines prostate biopsy was repeated after 6 months, because of the presence of extensive HGPIN or ASAP. Oral administration of pollen extract in association with vitamins (two capsules every 24 h) was prescribed until the repeat biopsy. Repeat biopsy histopathological examination showed, in 13 patients (68.4\%), a lower degree of inflammation (absent/mild/moderate).
\end{abstract}

KEY WORDS: Prostate; Phytotherapeutics; Benign prostatic hyperplasia.

Submitted 2 January 2019; Accepted 8 February 2019

\section{INTRODUCTION}

Chronic prostatic inflammation (CPI) leads to symptomatic or asymptomatic benign prostatic hyperplasia (BPH) $(1,2)$. Under the circumstances that CPI leads to BPH and, therefore, to lower urinary tract symptoms (LUTS) due to $\mathrm{BPH}, \mathrm{CPI}$ could be a target for medical treatment, in patients with asymptomatic or symptomatic BPH, acting on prostatic enlargement and LUTS.

Phytotherapeutics are a value options due to their generally minimal side-effects. The aim of the present caseseries analysis was to assess the safety and efficacy of pollen extract in association with vitamins (DEPROX $500^{\circledR}$ ) in order to reduce the chronic prostatic inflammation in patients with class IV chronic prostatitis (CP).

\section{Case presentation}

Nineteen non-consecutive patients performed a prostate biopsy for a suspect of prostate cancer (PCa). The biopsy

\section{Figure 1.}

Microscopic pathological features in hematoxylin and eosin stain: absent (a), mild (b), moderate (c), high (d) degree of inflammation.

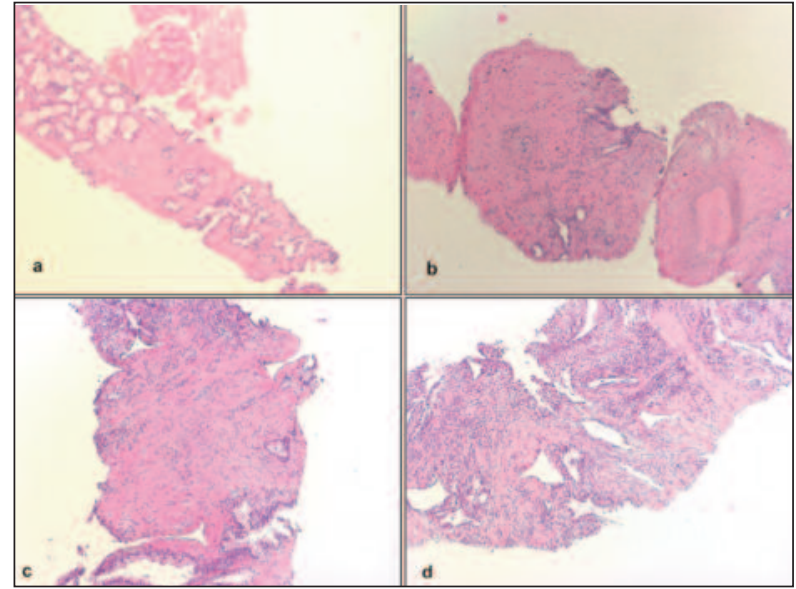

histopathological examination showed a class IV CP, in presence of mild/moderate/high degree of inflammation (Figure 1), in association with an extensive (multiple biopsy sites, i.e., $\geq 3$ ) high-grade prostatic intraepithelial neoplasia PIN (HGPIN) and/or atypical small acinar proliferation (ASAP).

About degree of inflammation, the biopsy histopathological examination showed in 6 patients (31.6\%) a mild degree of inflammation, in 9 patients (47.3\%) a moderate degree of inflammation and in 4 patients $(21.1 \%)$ an high degree of inflammation.

According to the classification of the National Institutes of Health (NIH), class IV chronic prostatitis (CP) are the asymptomatic inflammatory prostatitis (histological prostatitis) with no chronic pelvic pain syndrome (CPPS) (3). The mean patient age was $61.1 \pm 7.33$ years and the median IPSS score was 8 (6.5-13.5). The median prostate-specific antigen value, at biopsy, was $5.7 \mathrm{ng} / \mathrm{ml}$ (4.9-6.8 $\mathrm{ng} / \mathrm{ml}$ ). According to EAU Prostate Cancer Guidelines (4), a prostate biopsy was repeated, after 6 months, because of the presence of extensive HGPIN or ASAP. 
Figure 2.

a) Moderate degree of inflammation before the treatment; (b) mild degree of inflammation after the treatment.

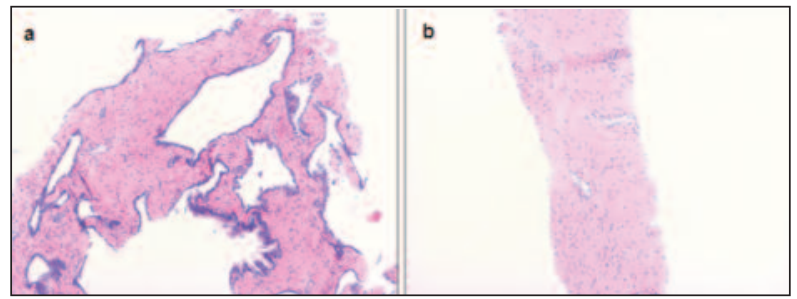

Table 1.

Degree of inflammation.

\begin{tabular}{|c|c|}
\hline $\begin{array}{l}\text { Degree of inflammation } \\
\text { (before DEPROX } 500^{\circledR} \text { ) - Pts }\end{array}$ & $\begin{array}{l}\text { Degree of inflammation } \\
\text { (after DEPROX 500 }{ }^{\circledR} \text { - Pts }\end{array}$ \\
\hline Mild - 6 Pts & Mild - 4 Pts \\
\hline Moderate - 9 Pts & Moderate - 7 Pts \\
\hline High - 4 Pts & High - 2 Pts \\
\hline
\end{tabular}

Under the circumstances of the histological prostatitis diagnosed, a medical oral administration of DEPROX $500^{\circledR}$ (two capsules every $24 \mathrm{~h}$ ) was prescripted until the repeat biopsy.

The repeat biopsy histopathological examination showed in 6 patients $(31.6 \%)$ prostate cancer, in 3 patients (15.8\%) extensive HGPIN or ASAP and in 10 patients (52.6\%) benign prostatic hyperplasia (BPH).

Moreover, the repeat biopsy histopathological examination showed, in 13 patients (68.4\%), a lower degree of inflammation (absent/mild/moderate). Specifically, 4 patients (30.8\%) showed absent instead of mild degree of inflammation, 7 patients (53.8\%) showed mild instead of moderate degree of inflammation (Figure 2) and 2 patients (15.4\%) showed moderate instead of high degree of inflammation (Table 1).

The median prostate-specific antigen value, at repeat biopsy, was $5.2 \mathrm{ng} / \mathrm{ml}(4.3-5.8 \mathrm{ng} / \mathrm{ml})$. DEPROX $500^{\circledR}$ was generally well tolerated over the full period.

\section{Discussion}

Chronic prostatic inflammation (CPI) leads to symptomatic or asymptomatic $\mathrm{BPH}(1,2)$.

$\mathrm{CPI}$ has been observed in a large proportion of patients treated surgically for lower urinary tract symptoms (LUTS) due to BPH and in the histological examination of prostatic biopsies performed for suspect of $\mathrm{PCa}$ (5). Moreover, CPI has been associated with higher prostate volume and a more severe International Prostate Symptom Score (IPSS) $(5,6)$.

Histologically, CPI is characterized by the presence of large confluent inflammatory nodules in prostatic tissue $(5,6)$.

These nodules release multiple inflammatory mediators that have been shown to stimulate prostatic cell growth. Nodules also damage the architecture of the gland, resulting in a chain reaction that further sustains the inflammatory response and promotes prostatic cell growth, prostatic enlargement, and bladder outlet obstruction (7).

A prostatic inflammation classification, based on a histologic grading related to the extension of inflammatory cells, has been described (8). Specifically, histologic grading can be classified as:

Grade 0 - absent, no inflammation;

Grade 1 - mild, scattered inflammatory cell infiltrate without nodules;

Grade 2 - moderate, no confluent lymphoid nodules; and Grade 3 - high, large inflammatory areas with confluence.

Under the circumstances that CPI leads to BPH and, therefore, to LUTS due to BPH, CPI could be a target for medical treatment, in patients with asymptomatic or symptomatic BPH, acting on prostatic enlargement and LUTS. In fact, it is described the favorable effects of nonsteroidal anti-inflammatory drugs (NSAIDs) (9), but their side effects related with long-term use mostly limit their prescription in patients with BPH-related LUTS.

Phytotherapeutics are a value options due to their generally minimal side-effects. In the present case-series analysis was observed that the use of pollen extract in association with vitamins (DEPROX $500^{\circledR}$ ) is safe and aids to reduce the severity of chronic prostatic inflammation in patients with class IV chronic prostatitis (CP). This effect is possibly due to the association between the pollen extract and vitamins B6 and B12 that improve the antioxidant activity and anti-inflammatory effect of pollen extract.

The present case-series analysis had few limitations that should be taken into account: the small number of enrolled patients, a short follow-up period, a selected patient population, the lack of control group and that this was not a blinded study.

\section{Conclusions}

The pollen extract in association with vitamins, such as DEPROX $500^{\circledR}$, could have a favorable effect in the reduction of chronic prostatic inflammation.

We expect further studies to evaluate its effect in chronic prostatic inflammation in the near future; in fact, more clinical data are needed to support the use of pollen extract in association with vitamins in a context of an evidence-based medicine. Currently, the use of this drug should be considered empirical.

\section{REFERENCES}

1. Ficarra V, Rossanese $M$, Zazzara $M$, et al. The role of inflammation in lower urinary tract symptoms (LUTS) due to benign prostatic hyperplasia (BPH) and its potential impact on medical therapy. Curr Urol Rep. 2014; 15:463.

2. Gandaglia G, Briganti A, Gontero P, et al. The role of chronic prostatic inflammation in the pathogenesis and progression of benign prostatic hyperplasia (BPH). BJU Int. 2013; 112:432-41.

3. Workshop Committee of the National Institute of Diabetes and Digestive and Kidney Disease (NIDDK). Chronic Prostatitis Workshop, Bethesda, MD, 7-8 December, 1995.

4. EAU-ESTRO-SIOG Guidelines on Prostate Cancer. Part 1: Screening, Diagnosis, and Local Treatment with Curative Intent. 
Mottet N, Bellmunt J, Bolla M, Briers E, Cumberbatch MG, De Santis M, Fossati N, Gross T, Henry AM, Joniau S, Lam TB, Mason MD, Matveev VB, Moldovan PC, van den Bergh RCN, Van den Broeck T, van der Poel HG, van der Kwast TH, Rouvière O, Schoots IG, Wiegel T, Cornford P. Eur Urol. 2017; 71:618-629.

5. Robert G, Descazeaud A, Nicolaiew $N$, et al. Inflammation in benign prostatic hyperplasia: A 282 patients' immunohistochemical analysis. Prostate. 2009; 69:1774-80.

6. Nickel JC, Roehrborn CG, O'Leary MP, et al. The relationship between prostate inflammation and lower urinary tract symptoms: examination of baseline data from the REDUCE trial. Eur Urol. 2008; 54:1379-84.
7. Kramer G, Mitteregger D, Marberger M. Is benign prostatic hyperplasia (BPH) an immune inflammatory disease? Eur Urol. 2007; 51:1202-16.

8. Irani J, Levillain P, Goujon JM, et al. Inflammation in benign prostatic hyperplasia: correlation with prostate specific antigen value. $J$ Urol. 1997; 157:1301-3.

9. Kahokehr A, Vather R, Nixon A, Hill AG. Non-steroidal antiinflammatory drugs for lower urinary tract symptoms in benign prostatic hyperplasia: Systematic review and meta-analysis of randomized controlled trials. BJU Int. 2013; 111:304-11.

\section{Correspondence}

Michele Zazzara, MD

michele.zazzara@gmail.com

Arjan Nazaraj, MD

ari.nazaraj@hotmail.it

Ottavio Colamonico, MD

ottaviocolamonico@gmail.com

Giuseppe Cardo, MD

giuseppecardo@hotmail.com

Giuseppe Mario Ludovico, MD

giuseppeludovico@hotmail.com

Urology Department, Ospedale Generale Regionale "F. Miulli"

Strada Prov. 127 Acquaviva - Santeramo Km. 4.100,

70021 Acquaviva delle Fonti (BA) (Italy)

Marcella Mastromauro, MD

marcella.mastromauro@libero.it

Pathological Anatomy Department, Ospedale Generale Regionale "F. Miulli" Acquaviva delle Fonti (BA), Italy 